\title{
SAÚDE SEM FAKE NEWS: ESTUDO E CARACTERIZAÇÃO DAS INFORMAÇÕES FALSAS DIVULGADAS NO CANAL DE INFORMAÇÃO E CHECAGEM DE FAKE NEWS DO MINISTÉRIO DA SAÚDE
}

\section{HEALTH WITHOUT FAKE NEWS: STUDY AND CHARACTERIZATION OF FALSE INFORMATION DISCLOSED IN THE INFORMATION CHANNEL AND CHECKING FAKE NEWS IN THE MININISTRY OF HEALTH}

\author{
Ana Carolina Pontalti MONARI ${ }^{1}$, Claudio BERTOLLI FILHO ${ }^{2}$
}

\begin{abstract}
Resumo
Este artigo tem o objetivo de analisar o canal de informações Saúde Sem Fake News, do Ministério da Saúde, com o intuito de identificar as principais características das fake news no âmbito da saúde pública e de traçar um perfil desse conteúdo. Diante dos dados, foi possível identificar que esse tipo de material busca oferecer ao público possibilidades de cura, receitas milagrosas, informações assustadoras sobre vacinação e alimentos poderosos com o intuito de solucionar problemas cotidianos dos cidadãos. O perfil elencado para as fake news é o de um conteúdo que usa adjetivos, itens audiovisuais para promover uma falsa veracidade e termos que estabelecem proximidade com o leitor. Para o estudo foram utilizadas as análises de conteúdo e hermenêutica, sob a luz das teorias de midiatização e fake news.
\end{abstract}

Palavras-chave: fake news, saúde, midiatização, análise de conteúdo, análise hermenêutica.

\begin{abstract}
This article aims to analyze the information channel Saúde Sem Fake News, produced by the Ministry of Health, in order to identify fake news main characteristics in public health and to establish a profile for this type of content. Based on the data we gathered, we identified that this type of material seeks to provide the public with possibilities for healing, miracle recipes, "alarming" information on vaccination and powerful foods with the aim of solving citizens' daily problems. A typical fake news profile presents content

\footnotetext{
1 Mestranda em Comunicação pelo Programa de Pós-Graduação em Comunicação e bacharela em Comunicação Social Jornalismo pela Faculdade de Arquitetura, Artes e Comunicação (FAAC) da Universidade Estadual Paulista Júlio de Mesquita Filho (Unesp), campus de Bauru (SP). E-mail: capmonari@gmail.com.

${ }^{2}$ Doutor em Ciências pela Universidade de São Paulo e Livre Docente em Antropologia pela Universidade Estadual Paulista Júlio de Mesquita Filho. Atualmente é Professor Adjunto na Universidade Estadual Paulista Júlio de Mesquita Filho. Tem experiência na área de Antropologia, com ênfase em Antropologia e Comunicação e Ensino de Ciências. E-mail: cbertolli@faac.unesp.br
} 
that uses adjectives and audiovisual content to promote a false truth and it has terms that establish proximity with the readers. For this study, we employed a content and hermeneutical analyses, in light of theories of mediatization and fake news.

Keywords: fake news, health, mediatization, content analysis, hermeneutic analysis. 
Introdução

O Ministério da Saúde do Brasil divulgou em setembro de 2018 um parecer que apontava que aplicativos de troca de mensagens e redes sociais dificultaram a população de se proteger de doenças como febre amarela, gripe e sarampo. De acordo com nota, publicada no site do governo federal ${ }^{3}$, boatos espalhados pelo WhatsApp, Twitter e Facebook, por exemplo, têm influenciado na queda do alcance das campanhas de vacinação promovidas no país desde 2016. Embora outros fatores tenham colaborado para essa diminuição, tais como a mudança da jornada de trabalho das pessoas e o sucesso das campanhas passadas, o compartilhamento de fake news é apontado pelo órgão como uma das principais razões para a queda de $70 \%$ a $75 \%$ no alcance das ações de imunização.

Histórias fabricadas, notícias falsas e boatos não são novidades no meio comunicacional. Existem exemplos desse tipo de fenômeno registrados desde o Império Romano até os dias atuais, principalmente após o surgimento e popularização da internet. Allcott e Gentzkow (2017) definem o termo fake news como sendo artigo noticioso produzido para ser intencionalmente falso e apto a ser verificado como tal, podendo, portanto, enganar os leitores que tiverem contato com esse material.

As redes sociais online e a cultura do compartilhamento proporcionaram um novo visual para que a desinformação se transformasse em um problema público. A capacidade que as notícias falsas têm de influenciar eleições, por exemplo, fizeram com o que o problema ganhasse visibilidade em diversas esferas da sociedade, além de criar a necessidade de se debater o assunto e desenvolver formas de combatê-lo.

As notícias falsas não ganharam espaço somente no âmbito político, mas também em outras áreas, tais como a saúde. Reportagem da Pesquisa Fapesp ${ }^{4}$ publicada em agosto de 2018 relata que especialistas não descartavam que as causas para a queda na vacinação se deviam a influência das fake news que circulam nas redes sociais e de uma incipiente ação de grupos contrários à imunização, também conhecidos como movimentos

3 BRASIL. Boatos e notícias falsas prejudicam campanhas de vacinação. Disponível em: $<$ http://www.brasil.gov.br/noticias/saude/2018/09/boatos-e-noticias-falsas-prejudicam-campanhas-devacinacao>. Acesso em: 4 jan. 2019.

4 PESQUISA FAPESP. As razões da queda da vacinação. Disponível em: < http://revistapesquisa.fapesp.br/2018/08/17/as-razoes-da-queda-na-vacinacao/>. Acesso em: 4 jan. 2019. 
antivacinação. De acordo com a revista, na Europa e nos Estados Unidos são mais comuns os grupos que não aderem à vacinação por alegarem razões religiosas e filosóficas ou por se embasarem em informações inverídicas.

Com o intuito de combater às notícias falsas, o governo brasileiro realizou em setembro uma campanha digital para debater e diminuir a circulação de boatos e mentiras sobre vacinação. Na ação, imagens e vídeos trouxeram exemplos de mensagens errôneas que se difundiram na internet e convidavam os cidadãos a refletirem sobre o conteúdo que compartilham nas redes sociais. Outra iniciativa, realizada, porém, de forma contínua, foi a criação do canal de comunicação do Ministério da Saúde chamado Saúde Sem Fake News no segundo semestre de 2018.

O objetivo do projeto é possibilitar que a população consulte se a notícia sobre saúde que recebeu nas redes sociais digitais é verdadeira ou falsa. O mecanismo funciona da seguinte maneira: o cidadão que receber esse tipo de conteúdo pode enviar de forma gratuita e anônima a mensagem para o número de WhatsApp (61) 99289-4640. De acordo com os termos de uso $^{5}$, depois do recebimento da mensagem, a equipe multimídia do Ministério da Saúde enviará a dúvida à área técnica responsável pelo assunto em questão, que analisará o conteúdo e fará sua apuração para, posteriormente, reenviar a mensagem para equipe multimídia, que responderá ao cidadão com um selo de "isto é notícia falsa" ou "isto é notícia verdadeira". Com o fim da ocorrência, a dúvida e a resposta serão publicadas no Portal Saúde (saude.gov.br/fakenews) e nos perfis oficiais do órgão público nas redes sociais, buscando esclarecer a população de modo geral.

Diante da problemática criada pela difusão de informações falsas no âmbito da saúde pública, este artigo visa identificar quais são as principais características das fake news sobre saúde compartilhadas por usuários de redes sociais digitais no Brasil. Para isso, será feita uma análise da iniciativa Saúde Sem Fake News, do Ministério da Saúde, uma vez que o canal de comunicação busca, justamente, esclarecer a população sobre mensagens virais que circulam na internet sobre essa temática.

\footnotetext{
${ }^{5}$ MINISTÉRIO DA SAÚDE. Termos de uso do canal Saúde Sem Fake News. Disponível em: < http://portalarquivos2.saude.gov.br/images/pdf/2018/agosto/24/saude-sem-fakenews-termos-de-uso.pdf>. Acesso em: 2 jan. 2019.
} 
Dividido em duas partes, este estudo irá discutir primeiramente o fenômeno das fake news nas redes sociais digitais em uma sociedade midiatizada, evidenciando que esse tipo de material se apropria, muitas vezes, da espetacularização das doenças para atingir sua audiência. E, por último, será feita uma análise do programa desenvolvido pelo órgão federal, identificando as principais características das notícias falsas decodificadas por eles e buscando traçar um perfil desse conteúdo. Teorias sobre midiatização e fake news darão aporte teórico ao artigo, que também contará com as análises de conteúdo e hermenêutica como aportes metodológicos.

\section{Sociedade midiatizada e a problemática das fake news}

A tecnologia mudou a forma como o homem se relaciona com o próximo e com os meios de comunicação. Sodré (2012) afirma que o "relacionamento do sujeito humano com a realidade obriga-se hoje a passar pela tecnologia, em especial as tecnologias da informação, em todos os seus modos de realização" (p. 364-365).

O acesso da população às tecnologias da informação proporcionou uma nova reconfiguração social, em uma sociedade que está em constante transformação, seja nos setores econômico, político, cultural ou social. Compreendendo que as teorias de comunicação acompanham as configurações sociais de cada época, é possível presumir que a sociedade se encontra em processo de midiatização.

No livro Antropológica do Espelho, Sodré (2002) faz a distinção entre os termos mediação e midiatização. Para ele, toda e qualquer cultura implica mediações simbólicas e o significado da ação de fazer ponte ou fazer comunicarem-se duas partes está presente na palavra mediação - o que implica, de acordo com o autor, em diferentes tipos de interação. Esse fato decorre, na verdade, de um poder originário de descriminar, de fazer distinções de um lugar simbólico, que seria fundador de todo o conhecimento. Com o intuito de fazer parte da ordem social, a mediação necessita ter uma base material, concretizada em instituições ou formas reguladoras do relacionamento com a sociedade - valores e normas institucionalizadas legitimam e outorgam sentido social às instituições. 
A midiatização, por outro lado, implica em mediações socialmente realizadas no sentido da comunicação como processo informacional, dependente das organizações empresariais e com ênfase em um tipo específico de interação, a tecnointeração, caracterizada pelo medium ${ }^{6}$.

É na sociedade midiatizada que aparece o fenômeno promovido pelos conteúdos falsos que passam a se chamar fake news. Esta temática ainda é recente no mundo acadêmico, mas pesquisas sobre o assunto destacam que sua ocorrência se dá devido à quebra de credibilidade da mídia de referência juntamente ao avanço da produção e compartilhamento de conteúdos nas redes sociais. Nota-se que a internet se tornou um cenário propício para que os usuários, tanto jornalistas como leitores leigos, sintam-se com liberdade de produzir, compartilhar e expressar suas opiniões e conceitos sobre quaisquer temas. Pesquisadores da área de comunicação e jornalistas, no entanto, observam uma tensão cada vez mais crescente, em seus ambientes de estudo e trabalho, visto que esse processo acaba depondo contra os princípios jornalísticos consagrados pelo jornalismo como os de agendamento, apuração junto à uma diversidade de fontes, confronto de versões contraditórias, entre outros, para a redação de notícias. Esse conjunto de fatores se transforma em um ambiente propício para elaboração e divulgação de fake news (ROCHA; LAVARDA; SILVEIRA, 2018).

Com o advento das redes sociais digitais, esse tipo de material passa a ser produzido e compartilhado pelos usuários, atingindo novos públicos em diferentes segmentos sociais e localidades. É possível, por exemplo, que uma "notícia” falsa que foi confeccionada em Manaus (AM) chegue a smartphones de São Paulo (SP), graças ao compartilhamento massivo feito pelos usuários, que divulgam o conteúdo na sua rede de amigos que, por sua vez, também repassam para seus próprios contatos. Esse mecanismo é repetido inúmeras vezes, o que ocasiona em uma difusão em que o próprio produtor acaba não tendo dimensão do seu alcance.

\footnotetext{
${ }^{6}$ Medium é um "dispositivo que emerge na cultura e na história no momento em que o processo da comunicação é redefinido pela informação, ou seja, por um regime até agora posto quase que exclusivamente a serviço da lei estrutural do valor, o capital. Esse regime é uma nova tecnologia societária, empenhada num outro tipo de hegemonia ético-política, em que se dissolve a configuração realística de mediações tradicionais" (SODRÉ, 2012, p. 362).
} 
Delmazo e Valente (2018) explicam que a própria forma como os links são compartilhados nas redes sociais digitais dificulta a identificação da natureza dos conteúdos que circulam na internet, ou seja, qualquer pessoa pode divulgar conteúdos falsos. Uma foto ou manchete - geralmente explícita na URL do link - feitas com o intuito de atrair o público já são suficientes para gerar engajamento, mesmo que eles não sejam clicados.

Os pesquisadores reforçam que as pessoas confiam primeiramente no próprio julgamento das fontes e da mensagem para afirmar a veracidade de determinado conteúdo. Quando essa medida não se mostra eficaz ou suficiente, elas buscam fontes externas para tentar essa autenticação, tais como os jornais. "Nesse processo, o volume de partilhas e o potencial de viralidade são comumente considerados como métricas de autenticidade e não apenas de popularidade" (DELMAZO; VALENTE, 2018, p. 158).

O consumo de notícias por sites e redes sociais digitais se apresenta como um dos comportamentos dos indivíduos na sociedade midiatizada. É cada vez mais comum que os usuários de internet façam a leitura de reportagens e escutem e vejam conteúdos jornalísticos desenvolvidos, em sua maioria, especialmente para as plataformas digitais celulares, tablets e computadores.

Um relatório do Instituto Reuters ${ }^{7}$ divulgado no primeiro semestre de 2018 aponta que o consumo de notícias está se transferindo das redes sociais, como o Facebook, para plataformas de mensagens como o WhatsApp. A pesquisa analisou 37 países de cinco continentes e concluiu que o consumo de notícias nas redes sociais caiu 6\% nos Estados Unidos em relação ao ano anterior. Há também, de acordo com o estudo, o aumento da desconfiança em relação às notícias divulgadas nestas plataformas. Embora o objetivo dos usuários ao expandir o seu consumo de notícias pelos aplicativos de troca de mensagens seja o de se manter informado, esse propósito nem sempre é alcançado, graças a disseminação de fake news, que se utilizam dessa plataforma para alcançar novas e maiores audiências.

\footnotetext{
7 EXAME. "WhatsApp cresce na consulta de notícias em detrimento do Facebook". Disponível em: < https://exame.abril.com.br/tecnologia/whatsapp-cresce-na-consulta-de-noticias-em-detrimento-dofacebook/>. Acesso em: 7 jan. 2019.
} 
Os dados apresentados vão de encontro ao pensamento de Llorente (2017) que afirma que todos os marcos de notícias falsas têm um denominador comum: as crenças pessoais ganham força frente à lógica e aos fatos e acabam estabelecendo-se como pressupostos difundidos pela sociedade, provocando a desordem da opinião pública. Nesse cenário, aparecem novas formas de relacionamento com a opinião pública e consolidam-se os meios de comunicação alternativos. As formas tradicionais de jornalismo, portanto, perdem peso com o advento dos novos canais de comunicação, tais como os blogs pessoais, o YouTube, as redes sociais digitais e os aplicativos de mensagens (WhatsApp, Telegram e o Facebook Messenger). Comentários feitos em qualquer uma dessas plataformas podem mobilizar muitas pessoas e causar resultados que seriam impensáveis há alguns anos, ainda mais se forem feitos por pessoas públicas ou por indivíduos que ocupam uma posição de destaque na sociedade (ROCHA; LAVARDA; SILVEIRA, 2018).

\section{Fake news no âmbito da saúde pública}

A problemática ocasionada pela disseminação de fake news está presente em todas as esferas da vida humana, porém, a área mais afetada por esse compartilhamento é a saúde pública, de acordo com a especialista em marketing digital Caroline Faillet, que é autora do livro "Décoder l'info - Comment Décrupter les fake news?" (2018). Em entrevista para o Opera Mundi ${ }^{8}$, ela salienta que o segmento é o mais prejudicado com a questão porque para que a informação falsa se propague, ela deve tocar as pessoas, deve estar relacionada à vida e ao cotidiano dos indivíduos. Diante desse pressuposto, a autora diz que não existem temas que atingem mais os cidadãos que a própria saúde e a alimentação, por isso, que é preciso desconfiar dos estudos e das informações divulgadas sobre esse assunto que circulem na internet.

$\mathrm{Na}$ mesma reportagem, ela reforça que artigos científicos pouco embasados e, muitas vezes, publicados em sites renomados podem representar um risco para a saúde

\footnotetext{
${ }^{8}$ OPERA MUNDI. "Saúde é a área mais afetada pelas fake news, diz especialista francesa". Disponível em: <https://operamundi.uol.com.br/sociedade/54508/saude-e-a-area-mais-afetada-pelas-fake-news-dizespecialista-francesa>. Acesso em: 11 jan. 2019.
} 
dos pacientes, uma vez que o objetivo desses portais é confundir a opinião pública, incluindo jornalistas, e dificultar a análise de comitês científicos. Faillet (2018) traz o dado de que existem cerca de 8 mil revistas de fake news científicas espalhadas pela web que são pagas para divulgar alguns desses estudos, algo que, segundo ela, pode se transformar em uma dificuldade para o trabalho da imprensa, mesmo a especializada no segmento.

Henriques (2018) afirma que a saúde é um bom meio de cultura para boatos e rápida circulação de notícias. De acordo com ele, isso ocorre porque a maior parte da população tem pouco conhecimento sobre a área e pela ansiedade que causam as notícias sobre doenças e epidemias. "É positivo que alertas e orientações cheguem logo para todos; entretanto, isso acontece com informações úteis e também com notícias falsas 'fake news', designação em inglês, que tem sido usada também no Brasil” (idem, p. 10).

Em uma sociedade midiatizada, o fenômeno das fake news se apropria da espetacularização da doença para atingir sua audiência e conseguir o maior número possível de compartilhamentos em diferentes esferas da população. Lefèvre (1999) afirma que o cotidiano é constituído por mitos e ritos e o campo da saúde e da doença não foge dessa regra. Sendo assim, as relações entre saúde, doença e mídia são evidentes - e problemáticas -, pois a mídia é, atualmente, a "grande máquina (no sentido chomskiano do termo) de produção de histórias mitológicas sobre saúde e doença” (p. 15). O autor ainda ressalta que:

(...) se reproduza, numa formação social como a nossa, a representação de que a saúde não é, como deveria ser, uma condição humana natural e generalizada, mas um bem de consumo, isto é, um permanente "estar", ou seja, algo sempre provisório, a ser obtido e permanente reobtido no mundo externo, no mercado. (...) Esse lugar-comum é mais um indicador de que a saúde é algo transitório, que se pode e que se costuma com frequência "perder", ao contrário da doença, entidade original e mais permanente (...) a saúde é, em síntese, um objeto de desejo disponível no mercado, tal desejo, que tem a sociedade capitalista de consumo como seu "local de ocorrência", só se concretiza plenamente, então, como atributo associado a produtos de (re) nome. (LEFÈVRE, 1999, p. 61-63-72). 
Diante do pressuposto de que a saúde é um item desejado não só do mercado, mas dos indivíduos, não fíca difícil compreender o aumento do compartilhamento de informações falsas sobre saúde pública. Se o conteúdo abordar a cura de doenças, o surgimento de alimentos milagrosos e receitas que podem trazer benefícios para a saúde, o usuário de redes sociais digitais irá se sentir compelido a divulgar o material entre os seus amigos, principalmente se receber a mensagem de indivíduos que fazem parte do seu círculo de conhecidos e de pessoas confiáveis.

Para Henriques (2018), existem vários tipos de interesse que podem levar à difusão de informações falsas no campo da saúde pública.

Foram mencionados motivos políticos, financeiros, religiosos e filosóficos; podem haver outros. Importante é que a informação adequada chegue oportunamente às pessoas de forma que elas confiem. O fortalecimento das instituições de saúde, de ensino e pesquisa, com investimento em suas interfaces de comunicação pode contribuir para que sejam reconhecidas como fonte de consulta para profissionais e a população. Campanhas de orientação podem ser úteis. Entretanto, como a população está mais exposta a risco quase não tem acesso à mídia, vivendo de forma intermitente ou contínua fora das cidades, o trabalho ativo de campo, sob responsabilidade de equipes de saúde familiarizadas e conhecidas nas localidades, levando informações e administrando vacinas, deve ser a grande prioridade para interromper a epidemia atual e melhorar o conhecimento público sobre a doença. (idem, p. 12).

O problema das notícias falsas tem gerado preocupações em organizações públicas e privadas, sendo que, muitas delas, buscaram elaborar projetos relacionados ao tema com o intuito de combatê-las. Entre as táticas encontradas e adotadas estão a de verificação de fatos por meio de agências de checagem e a capacitação de cidadãos para identificar e não disseminar conteúdos falsos.

Os veículos de comunicação, no entanto, também vêm para estabelecer um contraponto nesse sistema e para se afirmar como referências de informação de qualidade. Delmazo e Valente (2018) explicam que, além da checagem das mensagens falsas pelos meios de comunicação, é possível pesquisar por projetos de pesquisa que buscam monitorar conteúdos falsos e realizar processos de validação. Segundo os autores, existe 


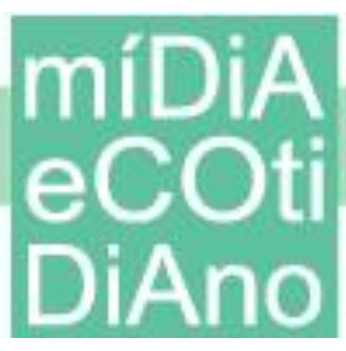

na Alemanha, por exemplo, uma legislação própria que busca se opor, com medidas mais severas, ao compartilhamento de fake news.

\section{Objetivos e metodologia}

O objetivo deste artigo é identificar quais são as principais características das fake news sobre saúde compartilhadas por usuários de redes sociais digitais no Brasil. Para isso, será feito um estudo sobre a iniciativa Saúde Sem Fake News, desenvolvida pelo Ministério da Saúde. A escolha desse canal de comunicação foi feita porque ele busca esclarecer a população sobre mensagens virais que circulam na internet sobre essa temática, por meio de um sistema de checagem e divulgação dos resultados no portal do programa.

Para fazer a investigação foram utilizadas a análise de conteúdo, preconizada por Laurence Bardin (2016) e a análise hermenêutica, pois ambas auxiliarão na identificação das características das informações falsas e proporcionarão subsídios para a criação de um perfil dessas notícias inverídicas. Bardin (2016) define a análise de conteúdo como sendo um:

(...) conjunto de técnicas de análise das comunicações visando obter por procedimentos sistemáticos e objetivos de descrição do conteúdo das mensagens indicadores (quantitativos ou não) que permitam a inferência de conhecimentos relativos às condições de produção/recepção (variáveis inferidas) dessas mensagens. (BARDIN, 2016, p. 48).

O objetivo dessa metodologia, portanto, é a inferência de conhecimentos relativos às condições de produção - ou eventualmente, de recepção -, inferência esta que recorre a indicadores (quantitativos ou não). Bardin (2016) explica que, dentre as técnicas propostas por essa análise, estão a do tipo temática e frequencial, que é "o método mais fácil, mais conhecido e mais útil numa primeira fase de abordagem da maioria dos materiais" (p. 55).

Para se aplicar a análise de conteúdo o pesquisador precisa seguir algumas diretrizes. Em um primeiro momento, ele fará uma leitura prévia do conteúdo a ser 
analisado e indicará hipóteses que poderão ser confirmadas ou não após a investigação do material. Posteriormente, ele fará um agrupamento por classificação (divisão por unidades significativas em categorias, rubricas ou classes), reunindo palavras ou frases que se encaixem nesses grupos pré-determinados por ele. Depois dessa divisão, é possível que o analista submeta o conteúdo à regra de enumeração que "corresponde ao seguinte postulado (válido em certos casos e em outros não): a importância de uma unidade de registro aumenta com a frequência de aparição" (idem, p. 138). Com os dados em mãos, ele poderá fazer a tabulação para, por meio de um recorte, estabelecer uma representação possível de ser interpretada.

Essa metodologia, no entanto, nem sempre oferece todos os subsídios para extrair as mensagens que estão por detrás do texto. Por isso, é necessário se utilizar de uma segunda ferramenta que, neste caso, será a análise hermenêutica, pois esta:

(...) procura mostrar o papel da interpretação como um processo, uma metodologia, que busca descobrir o originalmente escondido por uma tradição que nos foi legada por uma exegese distorcida, usando para tal uma destruição, ou seja, de uma desconstrução hermenêutica. A desconstrução hermenêutica, assim, não critica o passado, mas o presente e sua abordagem distorcida, subvertendo as explicações tradicionais e seus conceitos dogmaticamente inquestionados, não destruindo de fato, mas procurando revelar possibilidades ainda não percebidas. (BASTOS; PORTO; 2017, p. 317).

Retomando as ideias de Heidegger (apud SEIBT, 2016), o sociólogo John Thompson (2007) apresenta o método interpretativo da hermenêutica de profundidade, que consiste em três fases de análise e aborda, não apenas o caráter objetivo e formal do campo analisado, mas também sua dimensão subjetiva e essencialmente simbólica.

Em sua obra Ideologia e cultura moderna (2007), Thompson apresenta essas três etapas como sendo: análise sócio histórica, análise formal ou discursiva e interpretação/reinterpretação. Na primeira parte, o pesquisador irá investigar as condições sociais e históricas em que as formas simbólicas foram produzidas. Diante disso, é preciso descrever situações espaço-temporais, reconstruir ambientes ou campos de interação e suas regras, além das instituições sociais. Os meios técnicos de construção de mensagens e de transmissão também são estudados, uma vez que as formas simbólicas precisam se 


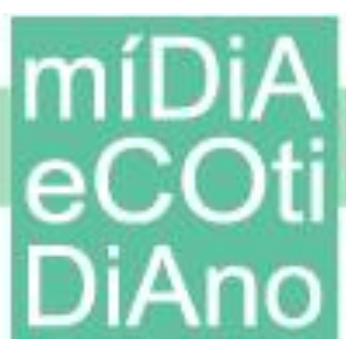

adequar a esses meios que, por sua vez, fazem parte de aparatos institucionais que lhe conferem características próprias (GOMES, 2015).

Durante a fase da análise formal ou discursiva, investiga-se a organização interna das formas simbólicas indicando suas características e relações estruturais. Para isso, o analista pode utilizar diversos métodos, tais como análise da conversação, semiótica e análise sintática, etc. A última etapa, chamada de interpretação/reinterpretação, proporciona um procedimento que sintetiza a análise formal ou discursiva apresentando possíveis significados e referências. (GOMES, 2015; THOMPSON, 2007).

O pesquisador, portanto, que utiliza essa metodologia faz uma ida e vinda ao texto, com o intuito de verificar os sentidos que estão escusos, fazendo um exercício de compreender e interpretar o conteúdo para revelar os significados que estão ocultos. A tarefa interpretativa, entretanto, é aberta e pode proporcionar significados divergentes daqueles propostos pelos sujeitos analisados, sendo, assim, uma projeção de significados possíveis. Em suma, a hermenêutica possibilita, meio da interrogação e da reinterpretação, reelaborar historicamente os sentidos e os significados da compreensão humana, estabelecendo, portanto, uma construção de uma ação comunicativa na abrangência da dimensão comunicacional (BASTOS; PORTO, 2017).

\section{Canal Saúde Sem Fake News}

Para a análise deste artigo foram considerados os questionamentos publicados no site do canal de comunicação Saúde Sem Fake News desde o início do programa (agosto de 2018) até 31 de dezembro de 2018. De acordo com o Ministério da Saúde ${ }^{9}$, nos três primeiros meses a plataforma recebeu 3.860 mensagens sobre diversos temas, sendo que 825 foram categorizadas como fake news. Embora tenham sido analisados um número expressivo de informações, apenas 33 questionamentos foram publicados no site do canal. As dúvidas publicadas são:

\footnotetext{
${ }^{9}$ MINISTÉRIO DA SAÚDE. "Conheça o serviço de combate às fake news do Ministério da Saúde". Disponível em: <http://portalms.saude.gov.br/noticias/agencia-saude/44852-servico-de-combate-as-fakesnews-do-ministerio-da-saude-e-destaque-no-fantastico>. Acesso em: 11 jan. 2019.
} 
Tabela 1 - Conteúdos verificados pelos analistas do Ministério da Saúde e divulgados no canal Saúde Sem Fake News.

\begin{tabular}{|c|c|c|c|}
\hline $\begin{array}{c}\text { Data de } \\
\text { publicação }\end{array}$ & $\begin{array}{l}\text { Título da } \\
\text { questão }\end{array}$ & Conteúdo & $\begin{array}{c}\text { Parecer do Ministério } \\
\text { da Saúde }\end{array}$ \\
\hline $24 / 08 / 2018$ & $\begin{array}{l}\text { Vacinação de } \\
\text { adultos contra o } \\
\text { sarampo. }\end{array}$ & $\begin{array}{l}\text { No período, estava em } \\
\text { curso uma campanha de } \\
\text { vacinação contra o } \\
\text { sarampo, cujo objetivo } \\
\text { era imunizar crianças de } \\
\text { um ano a menores de } 5 \\
\text { anos. }\end{array}$ & $\begin{array}{l}\text { Notícia verdadeira. } \\
\text { Embora não fosse o } \\
\text { público-alvo da ação, os } \\
\text { adultos não podem } \\
\text { descuidar de sua saúde e, } \\
\text { por isso, devem manter o } \\
\text { seu cronograma de } \\
\text { vacinação em dia. O } \\
\text { documento alertava que } \\
\text { as pessoas que tivessem o } \\
\text { seu esquema de } \\
\text { vacinação completo não } \\
\text { precisavam de doses } \\
\text { adicionais. }\end{array}$ \\
\hline $24 / 08 / 2018$ & $\begin{array}{ll}\text { Vacina } & \text { febre } \\
\text { amarela. } & \end{array}$ & $\begin{array}{l}\text { O conteúdo viral } \\
\text { alegava que } 60 \text { médicos } \\
\text { americanos pediam ao } \\
\text { mundo para não } \\
\text { tomarem a vacina contra } \\
\text { a febre amarela. }\end{array}$ & $\begin{array}{l}\text { Fake news. De acordo } \\
\text { com as normas do } \\
\text { Programa Nacional de } \\
\text { Imunizações, a vacina } \\
\text { contra febre amarela é } \\
\text { segura e eficaz quando } \\
\text { administrada de forma } \\
\text { correta. }\end{array}$ \\
\hline $28 / 08 / 2018$ & $\begin{array}{ll}\text { MPF } & \text { proíbe } \\
\text { vacina } & \text { contra } \\
\text { HPV. } & \end{array}$ & $\begin{array}{l}\text { Postagem publicada pela } \\
\text { página de Facebook } \\
\text { Cruzada pela Liberdade } \\
\text { anunciava que o } \\
\text { Ministério Público } \\
\text { Federal (MPF) havia } \\
\text { proibido a vacina contra } \\
\text { o Papilomavírus } \\
\text { Humano (HPV). }\end{array}$ & $\begin{array}{l}\text { Fake news. Não existe } \\
\text { nenhuma } \\
\text { contra o medicamento. }\end{array}$ \\
\hline $28 / 08 / 2018$ & 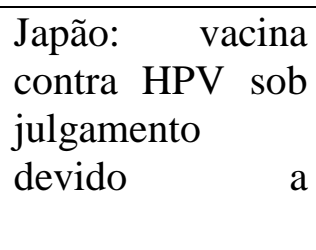 & $\begin{array}{l}\text { Novamente, a vacina } \\
\text { contra o HPV é colocada } \\
\text { como alvo de } \\
\text { questionamento. }\end{array}$ & $\begin{array}{l}\text { Fake news. O Ministério } \\
\text { da Saúde reafirma que } \\
\text { não há nenhuma } \\
\text { proibição } \\
\text { composto. }\end{array}$ \\
\hline
\end{tabular}




\begin{tabular}{|c|c|c|c|}
\hline & $\begin{array}{l}\text { horríveis efeitos } \\
\text { colaterais. }\end{array}$ & & \\
\hline 28/08/2018 & Jovem SUS. & $\begin{array}{l}\text { Divulgação } \text { da } \\
\text { campanha Jovem SUS. }\end{array}$ & $\begin{array}{l}\text { Fake news. Embora a } \\
\text { imagem divulgada sobre } \\
\text { a ação Jovem SUS seja } \\
\text { verdadeira, o conteúdo é } \\
\text { antigo - de agosto de } \\
2015 \text {. O programa foi } \\
\text { desenvolvido pela } \\
\text { Prefeitura de São Paulo } \\
\text { (SP) até 2017, ou seja, } \\
\text { não está mais em } \\
\text { vigência. }\end{array}$ \\
\hline 29/08/2018 & $\begin{array}{l}\text { Nova dipirona } \\
\text { importada da } \\
\text { Venezuela } \\
\text { contém vírus. }\end{array}$ & $\begin{array}{l}\text { Conteúdo trazia a } \\
\text { informação de que uma } \\
\text { dipirona importada da } \\
\text { Venezuela continha o } \\
\text { vírus "Marbug". }\end{array}$ & $\begin{array}{l}\text { Fake news. De acordo } \\
\text { com a Agência Nacional } \\
\text { de Vigilância Sanitária } \\
\text { (Anvisa) a informação de } \\
\text { que dipirona importada } \\
\text { da Venezuela contém o } \\
\text { vírus "Marbug" é falsa. }\end{array}$ \\
\hline 29/08/2018 & $\begin{array}{ll}\text { Suspensão } & \\
\text { nacional } & \text { da } \\
\text { fabricação } & \text { de } \\
\text { produtos } & \text { da } \\
\text { Rioquímica. } & \end{array}$ & $\begin{array}{l}\text { Nota sobre a suspensão } \\
\text { da fabricação de } \\
\text { produtos da Rioquímica. }\end{array}$ & $\begin{array}{l}\text { Notícia verdadeira. O } \\
\text { conteúdo foi publicado no } \\
\text { Diário Oficial da União } \\
\text { no dia } 23 \text { de agosto de } \\
2018 \text {. }\end{array}$ \\
\hline $29 / 08 / 2018$ & $\begin{array}{l}\text { Proibição da } \\
\text { importação e } \\
\text { venda do insumo } \\
\text { farmacêutico } \\
\text { ativo Valsartana. }\end{array}$ & $\begin{array}{l}\text { Nota sobre a proibição } \\
\text { da importação e venda } \\
\text { do insumo farmacêutico } \\
\text { ativo Valsartana. }\end{array}$ & $\begin{array}{l}\text { Notícia verdadeira. O } \\
\text { conteúdo foi publicado no } \\
\text { Diário Oficial da União } \\
\text { no dia } 24 \text { de agosto de } \\
2018 \text {. }\end{array}$ \\
\hline 29/08/2018 & $\begin{array}{l}\text { Bactéria } \\
\text { feijões. }\end{array}$ & $\begin{array}{l}\text { A informação veiculada } \\
\text { nas redes sociais pede } \\
\text { que a população coloque } \\
\text { o feijão de molho por } 15 \\
\text { minutos no vinagre, } \\
\text { pois, somente dessa } \\
\text { forma, poderia ser } \\
\text { eliminada uma bactéria } \\
\text { encontrada no alimento }\end{array}$ & $\begin{array}{l}\text { Fake news. O ministério } \\
\text { recorre a especialistas da } \\
\text { área para esclarecer que } \\
\text { não há necessidade desse } \\
\text { tipo de ação e que o } \\
\text { cozimento na panela de } \\
\text { pressão eliminaria } \\
\text { qualquer tipo de bactéria } \\
\text { comum que poderia estar } \\
\text { presente no feijão. }\end{array}$ \\
\hline
\end{tabular}




\begin{tabular}{|c|c|c|c|}
\hline & & $\begin{array}{lll}\text { e que viria } & \text { das } \\
\text { plantações. } & & \end{array}$ & \\
\hline $29 / 08 / 2018$ & $\begin{array}{ll}\text { Efeitos } & \text { da } \\
\text { glândula } & \text { da } \\
\text { próstata. } & \end{array}$ & $\begin{array}{lr}\text { Informação } & \text { que } \\
\text { circulava nas } & \text { redes } \\
\text { sociais apontava } & \text { sobre } \\
\text { os possíveis efeitos } \\
\text { provocados } & \text { pela } \\
\text { glândula da próstata. }\end{array}$ & $\begin{array}{l}\text { Fake news. Médico do } \\
\text { Instituto Nacional do } \\
\text { Câncer (Inca) foi } \\
\text { acionado para esclarecer } \\
\text { a população sobre o } \\
\text { conteúdo. }\end{array}$ \\
\hline 29/08/2018 & $\begin{array}{ll}\text { Banana } & \text { com } \\
\text { vírus HIV. } & \end{array}$ & $\begin{array}{l}\text { Conteúdo alegava que a } \\
\text { banana poderia } \\
\text { transmitir o vírus HIV. }\end{array}$ & $\begin{array}{l}\text { Fake news. O contágio } \\
\text { pelo vírus HIV não se dá } \\
\text { por contato com roupas, } \\
\text { objetos ou outros } \\
\text { alimentos. A informação } \\
\text { de que a banana poderia } \\
\text { transmitir o vírus, } \\
\text { portanto, é falsa. }\end{array}$ \\
\hline $30 / 08 / 2018$ & $\begin{array}{l}\text { Vacina } \\
\text { anticâncer. }\end{array}$ & $\begin{array}{l}\text { O conteúdo informa que } \\
\text { a unidade hospitalar } \\
\text { teria desenvolvido uma } \\
\text { vacina contra o câncer. }\end{array}$ & $\begin{array}{l}\text { Fake news. O Hospital } \\
\text { Sírio-libanês } \\
\text { esclareceu informação, } \\
\text { que circula desde } 2008 .\end{array}$ \\
\hline $30 / 08 / 2018$ & $\begin{array}{lr}\text { Coletes } & \text { de } \\
\text { agentes } & \\
\text { endêmicos de } \\
\text { controle de } \\
\text { dengue roubados. }\end{array}$ & $\begin{array}{l}\text { Nota trazia a informação } \\
\text { de que foram roubados } \\
\text { coletes e bolsas de } \\
\text { agentes endêmicos de } \\
\text { controle de dengue para } \\
\text { serem usados em furtos } \\
\text { de residências. }\end{array}$ & $\begin{array}{l}\text { Fake news. Não se há } \\
\text { notícia, de acordo com o } \\
\text { Saúde Sem Fake News, de } \\
\text { que existam quadrilhas } \\
\text { em diversas cidades } \\
\text { utilizando esse tipo de } \\
\text { disfarce para cometer } \\
\text { crimes. }\end{array}$ \\
\hline $03 / 09 / 2018$ & $\begin{array}{l}\text { Vacina } \\
\text { obrigatórias. }\end{array}$ & $\begin{array}{l}\text { O canal traz a } \\
\text { informação de que um } \\
\text { portal estaria divulgando } \\
\text { fake news na internet, } \\
\text { com a publicação de } \\
\text { informações inverídicas } \\
\text { sobre vacinação. }\end{array}$ & Fake news. \\
\hline 05/09/2018 & $\begin{array}{ll}\text { "Peste } & \text { Negra" } \\
\text { ameaça } & \text { voltar à } \\
\text { Paraíba. } & \end{array}$ & $\begin{array}{lrr}\text { Conteúdo mostra uma } & \text { motria do } \\
\text { suposta } & \text { notícia do } \\
\text { Correio da } & \text { Paraíba sobre }\end{array}$ & $\begin{array}{l}\text { Fake news. O Brasil não } \\
\text { registra casos de peste } \\
\text { humana desde } 2005 \text {. }\end{array}$ \\
\hline
\end{tabular}




\begin{tabular}{|c|c|c|c|}
\hline & & $\begin{array}{l}\text { a volta da peste negra ao } \\
\text { estado nordestino. }\end{array}$ & \\
\hline 05/09/2018 & $\begin{array}{l}\text { Cura da diabetes } \\
\text { com cápsula } \\
\text { natural. }\end{array}$ & $\begin{array}{l}\text { Site traz a notícia de que } \\
\text { mais de } 2 \text { milhões de } \\
\text { pessoas no mundo } \\
\text { estariam vencendo a } \\
\text { diabetes com o auxílio } \\
\text { de cápsulas naturais. }\end{array}$ & $\begin{array}{l}\text { Fake news. O canal } \\
\text { novamente traz para o } \\
\text { público o alerta sobre um } \\
\text { portal que divulga } \\
\text { informações ráno } \\
\text { verificadas ou inverídicas } \\
\text { sobre saúde pública. }\end{array}$ \\
\hline 06/09/2018 & $\begin{array}{l}\text { Uso do celular no } \\
\text { escuro e o câncer } \\
\text { de olho. }\end{array}$ & $\begin{array}{l}\text { Texto com o título "Uso } \\
\text { do Celular no Escuro" } \\
\text { faz uma relação entre } \\
\text { esse tipo de ação e a } \\
\text { maculopatia. }\end{array}$ & $\begin{array}{l}\text { Fake news. Não existem } \\
\text { estudos científicos que } \\
\text { comprovem que o uso do } \\
\text { celular, seja de noite ou } \\
\text { de dia, provoque } \\
\text { maculopatia }- \text { texto } \\
\text { classifica essa doença } \\
\text { como câncer de olho -, } \\
\text { catarata, olho seco, } \\
\text { degeneração celular ou } \\
\text { perda da visão. }\end{array}$ \\
\hline $21 / 09 / 2018$ & $\begin{array}{l}\text { Beber água antes } \\
\text { de pintar o } \\
\text { cabelo. }\end{array}$ & $\begin{array}{l}\text { O conteúdo veiculado } \\
\text { nas redes sociais pede } \\
\text { que a pessoa faça a } \\
\text { ingestão de água durante } \\
\text { todo o tempo de ação da } \\
\text { tintura de cabelo, } \\
\text { mantendo a bexiga cheia } \\
\text { e só esvaziando-a após } \\
\text { lavar os cabelos como } \\
\text { forma de precaução, } \\
\text { buscando, assim, evitar } \\
\text { que partículas de } \\
\text { chumbo que as tinturas } \\
\text { contêm não fiquem } \\
\text { depositadas na bexiga, } \\
\text { que é para onde elas } \\
\text { seriam direcionadas, } \\
\text { prevenindo o } \\
\text { surgimento de câncer. }\end{array}$ & $\begin{array}{l}\text { Fake news. De acordo } \\
\text { com o ministério, essa é } \\
\text { uma interpretação muito } \\
\text { superficial sobre a } \\
\text { cinética do chumbo no } \\
\text { organismo e que o ato } \\
\text { proposto pelo conteúdo } \\
\text { veiculado na internet } \\
\text { pode ainda levar maior } \\
\text { quantidade de chumbo } \\
\text { aos tecidos } \\
\text { mineralizados, } \\
\text { favorecendo seu acúmulo } \\
\text { em ossos e dentes, ao } \\
\text { invés de contribuir para } \\
\text { sua eliminação. }\end{array}$ \\
\hline $24 / 09 / 2018$ & $\begin{array}{l}\text { Vacina causa } \\
\text { autismo. }\end{array}$ & $\begin{array}{l}\text { Texto informa de que } \\
\text { existem novas vacinas } \\
\text { que podem causar }\end{array}$ & $\begin{array}{l}\text { Fake news. Não há } \\
\text { evidência de uma ligação } \\
\text { entre vacina e } \quad \text { o }\end{array}$ \\
\hline
\end{tabular}




\begin{tabular}{|c|c|c|c|}
\hline & & $\begin{array}{l}\text { autismo e de que os } \\
\text { governos supostamente } \\
\text { saberiam desse fato. }\end{array}$ & $\begin{array}{l}\text { autismo/transtornos } \\
\text { autistas. }\end{array}$ \\
\hline 25/09/2018 & $\begin{array}{l}\text { Fenilpropalamina } \\
\text { em } \\
\text { medicamentos. }\end{array}$ & $\begin{array}{l}\text { O texto traz a } \\
\text { informação de que a } \\
\text { substância chamada } \\
\text { fenilpropalamina, } \\
\text { suspensa pela Anvisa } \\
\text { em 2000, ainda está } \\
\text { presente em } 22 \\
\text { medicamentos. }\end{array}$ & $\begin{array}{l}\text { Fake news. Há } 17 \text { anos a } \\
\text { fenilpropalamina não } \\
\text { existe no mercado } \\
\text { brasileiro. }\end{array}$ \\
\hline 27/09/2018 & $\begin{array}{lr}\text { Hospital } & \text { Mário } \\
\text { Kroeff } & \text { e } \\
\text { mamografia. } & \end{array}$ & \begin{tabular}{lrr} 
Conteúdo & \multicolumn{1}{c}{ trazia } & a \\
informação & de que & a \\
unidade & hospitalar \\
estaria & recebendo \\
agendamentos & para \\
mamografias & gratuitas \\
pelo telefone. &
\end{tabular} & $\begin{array}{l}\text { Fake news. Nota é falsa e } \\
\text { foi desmentida pela } \\
\text { própria instituição. }\end{array}$ \\
\hline $03 / 10 / 2018$ & $\begin{array}{l}\text { Chá de folhas de } \\
\text { graviola cura o } \\
\text { câncer. }\end{array}$ & $\begin{array}{l}\text { Mensagem divulgada } \\
\text { via redes sociais } \\
\text { apontava a relação entre } \\
\text { o chá de folhas de } \\
\text { graviola e a cura do } \\
\text { câncer. }\end{array}$ & $\begin{array}{l}\text { Fake news. Não há } \\
\text { evidências científicas de } \\
\text { que o chá de folhas de } \\
\text { graviola cure o câncer. }\end{array}$ \\
\hline $04 / 10 / 2018$ & $\begin{array}{l}\text { Paracetamol e } \\
\text { vírus Machupo. }\end{array}$ & $\begin{array}{l}\text { O texto veiculado nas } \\
\text { redes sociais trazia a } \\
\text { alegação de que o } \\
\text { medicamento } \\
\text { paracetamol contém o } \\
\text { vírus machupo, } \\
\text { considerado um dos } \\
\text { vírus mais perigosos do } \\
\text { mundo. }\end{array}$ & $\begin{array}{l}\text { Fake news. De acordo } \\
\text { com o ministério, a } \\
\text { Anvisa garante que a } \\
\text { confiabilidade dos } \\
\text { compostos medicamentos } \\
\text { disponibilizados no } \\
\text { mercado é assegurada por } \\
\text { rígidos critérios de } \\
\text { qualidade. }\end{array}$ \\
\hline $17 / 10 / 2018$ & $\begin{array}{l}\text { Contrato } \\
\text { emergencial do } \\
\text { SAMU sem } \\
\text { experiência. }\end{array}$ & $\begin{array}{l}\text { Nota informava de que } \\
\text { havia um processo } \\
\text { seletivo simplificado } \\
\text { para contratação } \\
\text { emergencial no SAMU. }\end{array}$ & $\begin{array}{l}\text { Fake news. Não há } \\
\text { informações } \\
\text { contratações do Serviço } \\
\text { de Atendimento Móvel de } \\
\text { Urgência (SAMU). }\end{array}$ \\
\hline
\end{tabular}




\begin{tabular}{|c|c|c|c|}
\hline $08 / 11 / 2018$ & $\begin{array}{l}\text { Limonada quente } \\
\text { cura o câncer. }\end{array}$ & $\begin{array}{l}\text { Mensagem divulgada } \\
\text { nas redes sociais } \\
\text { recomendava a ingestão } \\
\text { de limonada quente para } \\
\text { a cura do câncer. }\end{array}$ & $\begin{array}{l}\text { Fake news. Beber água } \\
\text { com limão não mata } \\
\text { células cancerígenas. }\end{array}$ \\
\hline $09 / 11 / 2018$ & $\begin{array}{l}\text { Besouros que } \\
\text { causam cegueira. }\end{array}$ & $\begin{array}{l}\text { Texto que circulava nas } \\
\text { redes sociais trazia o } \\
\text { relato de que um } \\
\text { besouro potó teria } \\
\text { deixado um homem } \\
\text { cego depois de entrar em } \\
\text { seu ouvido. }\end{array}$ & Fake news. \\
\hline $21 / 11 / 2018$ & $\begin{array}{l}\text { Cura do câncer } \\
\text { por alimentos } \\
\text { milagrosos. }\end{array}$ & $\begin{array}{l}\text { Mensagem propagada } \\
\text { nas redes sociais contém } \\
\text { afirmações do Dr. } \\
\text { Gupta, que aponta } \\
\text { alimentos milagrosos } \\
\text { para cura do câncer. }\end{array}$ & $\begin{array}{l}\text { Fake news. O Saúde Sem } \\
\text { Fake News informa que, } \\
\text { apesar da diminuição do } \\
\text { açúcar trazer benefícios } \\
\text { para a saúde, não há } \\
\text { alimentos ou medidas } \\
\text { milagrosas capazes de } \\
\text { eliminar o câncer após } \\
\text { sua instalação. }\end{array}$ \\
\hline $22 / 11 / 2018$ & $\begin{array}{l}\text { Água quente de } \\
\text { coco e a cura do } \\
\text { câncer. }\end{array}$ & $\begin{array}{l}\text { Outra mensagem } \\
\text { difundida nas redes } \\
\text { sociais que faz a relação } \\
\text { entre um alimento (no } \\
\text { caso, a água quente do } \\
\text { coco) e a cura do câncer. }\end{array}$ & $\begin{array}{l}\text { Fake news. Não existe um } \\
\text { alimento específico ou } \\
\text { milagroso para a } \\
\text { prevenção e/ou cura do } \\
\text { câncer. }\end{array}$ \\
\hline $26 / 11 / 2018$ & $\begin{array}{l}\text { Refrigerantes, } \\
\text { falta de atividade } \\
\text { renal e tumores. }\end{array}$ & $\begin{array}{l}\text { Conteúdo faz a relação } \\
\text { entre a ingestão de } \\
\text { refrigerante, falta de } \\
\text { atividade renal e o } \\
\text { surgimento de tumores. }\end{array}$ & $\begin{array}{l}\text { Fake news. Esse } \\
\text { conteúdo, que circula na } \\
\text { internet desde 2006, já foi } \\
\text { desmentido pela } \\
\text { Sociedade Brasileira de } \\
\text { Cardiologia. }\end{array}$ \\
\hline $05 / 12 / 2018$ & $\begin{array}{lr}\text { Guardar } & \text { cebola } \\
\text { cortada } & \text { é } \\
\text { altamente } & \\
\text { perigoso. } & \end{array}$ & $\begin{array}{l}\text { O áudio propagado via } \\
\text { redes sociais trazia a } \\
\text { notícia de que guardar } \\
\text { cebola cortada na } \\
\text { geladeira poderia ser } \\
\text { maléfico para a saúde. }\end{array}$ & $\begin{array}{l}\text { Fake news. Citada como } \\
\text { autora do conteúdo, a } \\
\text { médica Marinella Della } \\
\text { Negro desmente ter } \\
\text { gravado o áudio } \\
\text { veiculado nas redes } \\
\text { sociais e também não }\end{array}$ \\
\hline
\end{tabular}




\begin{tabular}{|c|c|c|c|}
\hline & & & $\begin{array}{l}\text { avaliza qualquer } \\
\text { informação repassada. }\end{array}$ \\
\hline $05 / 12 / 2018$ & $\begin{array}{l}\text { Quiabo cura } \\
\text { diabetes. }\end{array}$ & $\begin{array}{l}\text { Nota informava de que o } \\
\text { programa de televisão } \\
\text { da } T V \text { Globo Caldeirão } \\
\text { do Huck teria divulgado } \\
\text { uma descoberta de três } \\
\text { jovens sobre a cura da } \\
\text { diabetes por meio da } \\
\text { ingestão do quiabo. }\end{array}$ & $\begin{array}{l}\text { Fake news. Diabetes é } \\
\text { uma doença crônica e, até } \\
\text { o momento, não tem cura. } \\
\text { A Sociedade Brasileira de } \\
\text { Diabetes (SBD) emitiu } \\
\text { comunicado alertando } \\
\text { sobre essa fake news. }\end{array}$ \\
\hline $05 / 12 / 2018$ & $\begin{array}{l}\text { Óleo no umbigo } \\
\text { cura doenças. }\end{array}$ & $\begin{array}{l}\text { Notícia aponta que o } \\
\text { umbigo seria um } \\
\text { presente incrível de } \\
\text { Deus e que todas as } \\
\text { veias do corpo humano } \\
\text { estariam ligadas a ele. } \\
\text { Por isso, ao colocar óleo } \\
\text { no umbigo o usuário } \\
\text { poderia curar diversas } \\
\text { doenças. }\end{array}$ & $\begin{array}{l}\text { Fake news. Não há } \\
\text { efetivamente uma } \\
\text { fórmula "mágica" para a } \\
\text { cura de todas as doenças, } \\
\text { como alega o canal de } \\
\text { comunicação. }\end{array}$ \\
\hline $05 / 12 / 2018$ & $\begin{array}{l}\text { Água gelada faz } \\
\text { mal. }\end{array}$ & $\begin{array}{lrr}\text { Conteúdo } & \text { destaca os } \\
\text { supostos } & \text { males } \\
\text { provocados } & \text { pela } & \text { água } \\
\text { gelada. } & & \end{array}$ & $\begin{array}{l}\text { Fake news. De acordo } \\
\text { com o Saúde Sem Fake } \\
\text { News, o texto compartilha } \\
\text { informações falsas } \mathrm{e} \\
\text { alarmistas sobre } \\
\text { assunto. }\end{array}$ \\
\hline
\end{tabular}

Fonte: elaborada pela autora com informações do Ministério da Saúde.

O canal Saúde Sem Fake News recebeu 33 questionamentos sobre saúde pública, sendo que desse total de dúvidas apenas três mensagens foram consideradas como notícias verdadeiras. O restante foi categorizado como fake news, podendo ser feito um novo agrupamento, dessa vez por temáticas.

As perguntas dos usuários que levaram às fake news foram submetidas novamente a análise de conteúdo, porém, elas foram decodificadas por categorias prévias, sendo elas: cura, vacinação, câncer, remédios ou alimentos que contêm vírus ou bactérias e diabetes. Dessa forma, pretende-se contabilizar o número de inserções que essas palavras aparecem nas mensagens falsas. 
Tabela 2 - Questões do Saúde Sem Fake News submetidas à regra de enumeração de Bardin (2016).

\begin{tabular}{|l|l|}
\hline \multicolumn{1}{|c|}{ Categorias } & \multicolumn{1}{c|}{ Frequência } \\
\hline Cura & 8 inserções \\
\hline Vacinação & 7 inserções \\
\hline Câncer & 6 inserções \\
\hline Remédios ou alimentos que contêm vírus & 4 inserções \\
\hline ou bactérias & 2 inserções \\
\hline Diabetes & \\
\hline
\end{tabular}

Fonte: elaborada pela autora.

O quadro acima (Tabela 2) aponta para um grande número de inserções da palavra cura nas mensagens categorizadas como fake news. O termo está atrelado, geralmente, as palavras câncer (seis inserções) e diabetes (duas inserções), enfermidades cujos números de portadores são grandes no Brasil - o Instituto Nacional do Câncer (INCA) estima 600 mil novos casos de câncer somente para o ano de 2019 (INCA, 2017) e a Organização Mundial de Saúde (OMS) aponta que 16 milhões de brasileiros sofrem atualmente de diabetes ${ }^{10}$.

O vocábulo também está relacionado a ingestão de alimentos naturais ou que são facilmente encontráveis, tais como chá de graviola, limonada quente, água de coco quente e quiabo. São itens quase sempre presentes nos lares das pessoas e que fazem parte do seu cotidiano. Essas notícias falsas costumam ser compartilhadas entre os usuários de redes sociais, que passam esses conteúdos entre seus amigos ou familiares, o que

\footnotetext{
${ }^{10}$ FIOCRUZ. "Taxa de incidência de diabetes cresceu $61,8 \%$ nos últimos 10 anos". Disponível em: <https://portal.fiocruz.br/noticia/taxa-de-incidencia-de-diabetes-cresceu-618-nos-ultimos-10-anos>. Acesso em: 11 jan. 2019.
} 
comprova o pressuposto defendido por Delmazo e Valente (2018) e por Faillet (2018) de que as pessoas confiam primeiramente no próprio julgamento das fontes e das mensagens para afirmar a veracidade de determinada informação, além de confiarem na premissa de quanto mais compartilhamentos mais confiável a notícia tende a ser.

Os movimentos antivacina, que ganharam força e adeptos na internet, podem ser a explicação para o termo vacinação aparecer com grande frequência (sete aparições) nas inserções das mensagens consideradas falsas pelo Ministério da Saúde. Nas últimas três décadas, a mídia destaca eventos adversos ligados à imunização contra difteria/tétano/coqueluche, hepatite e a vacina tríplice, o que pode ter influenciado essa aversão de diversos pais ao medicamento e a sua adesão ao movimento antivacinação (HENRIQUES, 2018). Outro fator que pode ter contribuído para essa ação, é a associação entre a vacina tríplice contra sarampo, caxumba e rubéola e o autismo (VASCONCELLOS-SILVA; CASTIEL; GRIEP, 2015). Embora não seja comprovada essa relação entre o composto medicamentoso e os transtornos do espectro autista, ainda existem pais que acreditam nessa afirmação e buscam não vacinar seus filhos, o que colaborou para o reaparecimento de doenças que eram consideradas erradicadas há anos.

Remédios ou alimentos que contêm vírus ou bactérias é a categoria que aparece com quatro inserções, o que demonstra que as mensagens que informam sobre maneiras de evitar contágios pela ingestão de medicamentos ou alimentos são bastante compartilhadas nas redes sociais - mesmo que sejam falsas. Esse tipo de informação aparenta, em um primeiro momento, ser de utilidade pública, principalmente pelos títulos - que são, por exemplo, "Banana com vírus HIV" e "Bactéria nos feijões" - e pelo conteúdo, que busca trazer soluções para que os indivíduos consigam contornar a situação - tais como "deixar o feijão de molho no vinagre por 15 minutos". O conteúdo se aproxima, portanto, do praticado pelo jornalismo cidadão, como exemplifica Amorim (2012):

No esforço de aproximação do leitor, o jornal passou a se pautar pela prática do jornalismo cívico ou cidadão, um movimento de renovação do jornalismo, iniciado nos Estados Unidos, organizado em torno dos seguintes princípios: a) cobertura de assuntos próximos do dia a dia e do entorno imediato dos cidadãos; b) apontar problemas, mas debate- 
los procurando encaminhar possíveis soluções; c) participação do leitor. (Idem, p. 397).

Por apresentar informações que pertencem ao dia a dia do cidadão, tais como a alimentação, as fake news conseguem maior compartilhamento entre os usuários de redes sociais digitais e ao oferecer soluções práticas para resolver esses mesmos impasses, esses conteúdos obtêm maior penetração e circulação entre diferentes cidades e segmentos da sociedade. É por meio da espetacularização da doença e pela promessa de medicamentos e receitas milagrosas que as informações falsas circulam nos aplicativos de mensagens e na internet (LEFÈVRE, 1999).

É necessário compreender a maneira como são construídos os discursos das notícias falsas na sociedade midiatizada (SODRÉ, 2002). Nas mensagens divulgadas pelo Saúde Sem Fake News é possível perceber que os autores não se preocupam com formas de mensagens muito elaboradas, porém se utilizam de imagens, fotos ou áudios para conferir falsa credibilidade e atingir o maior número de pessoas. Um exemplo é a notícia falsa sobre o ato de guardar cebola cortada na geladeira, que oferecia ao indivíduo um áudio da médica Marinella Della Negro. O ato de trazer um especialista no assunto pode oferecer uma credibilidade ao conteúdo que não é verdadeira (DELMAZO; VALENTE, 2018).

Os criadores de informações inverídicas também se utilizam de chamadas com o uso de adjetivos, o que não é comum no jornalismo, tais como "Japão: vacina contra HPV sob julgamento devido a horríveis efeitos colaterais" (divulgada em 28 de agosto de 2018), "Peste Negra' ameaça voltar à Paraíba" (divulgada em 5 de setembro de 2018), "Vírus Machupo é considerado como um dos mais perigosos do mundo" (disponível no corpo da mensagem divulgada pelo canal em 4 de outubro de 2018), "Cura do câncer por alimentos milagrosos" (divulgada em 21 de novembro de 2018) e "Guardar cebola cortada é altamente perigoso" (divulgada em 5 de dezembro de 2018).

Rodrigues (2012) explica que o discurso midiático faz o uso predominante da $3^{\text {a }}$ pessoa para criar um efeito de completude, que garante uma estratégia de universalidade referencial aos enunciados e uma credibilidade da narração dos fatos independente do lugar de fala do enunciador. Embora as fake news se utilizem, em muitos casos do 
emprego da $3^{\text {a }}$ pessoa, as frases geralmente são construídas com o uso de adjetivos, o que as aproxima das expressões escritas/verbais das pessoas que serão atingidas pelo seu conteúdo. A utilização desses termos confere, além de identificação, alarmismo, pois buscam assustar e advertir o usuário para os potenciais riscos presentes no uso de medicamentos ou no consumo de alimentos. É preciso, portanto, desconfiar de textos que contêm palavras que indicam qualidades de forma expressiva, tais como os exemplos obtidos na análise do Saúde Sem Fake News: "perigoso", "ameaça" e "horríveis".

Em suma, o canal do Ministério da Saúde identifica tipos de fake news que podem ser encontradas no âmbito da saúde pública. Entre as inúmeras possibilidades que estão disponíveis na internet, o público poderá se deparar com receitas milagrosas para curar o câncer, informações alarmantes sobre vacinas, alimentos e remédios contaminados com vírus e bactérias, uso de coletes de agentes de endemias para a realização de furtos a residências e consumo de frutas quentes para o tratamento de doenças, entre outras. $\mathrm{O}$ usuário de redes sociais deve, portanto, desconfiar das mensagens recebidas, principalmente, em seu WhatsApp e fazer uma checagem em agências de notícias ou portais, tais como o Saúde Sem Fake News.

Os materiais classificados como notícias falsas nem sempre são fáceis de serem reconhecidos. Os itens textuais aparecem, geralmente, acompanhados de fotos, infográficos, áudios e vídeos, o que dificulta o discernimento do público, uma vez que nomes de especialistas são utilizados, muitas vezes sem a devida autorização, para conferir autoridade ao conteúdo transmitido. É preciso, portanto, que os indivíduos desconfiem de qualquer informação recebida de terceiros, fazendo uma checagem para não caírem, por exemplo, em golpes ou para não divulgarem mensagens com dados inverídicos, que podem gerar alarmismos na população sem a real necessidade.

O perfil de fake news que pode ser traçado diante dos dados obtidos pelo canal de comunicação é o de uma mensagem que opta por palavras que remetem aos termos "perigo", "ameaça" e "cura", o que pode estar relacionado a espetacularização da doença e a propagação de soluções para problemas cotidianos dos cidadãos. Outra característica é a utilização de adjetivos, algo que não está presente na rotina jornalística, e a busca pela proximidade com o público por meio do texto, do áudio, do vídeo ou da foto. Com essas 
particularidades, o usuário de redes sociais digitais pode ter um prelúdio do que são informações verdadeiras ou falsas, impedindo o compartilhamento de boatos ou notícias inverídicas na web.

\section{Considerações finais}

As fake news se tornaram um fenômeno e uma problemática da sociedade midiatizada. Com o grande compartilhamento de informações pelas redes sociais digitais e, sobretudo, pelos aplicativos de mensagens, é inevitável que o usuário acabe por ter contato com esse tipo de material, mesmo com todas as precauções possíveis e com capacitações próprias para buscar a checagem de todo o conteúdo que recebe.

Organizações públicas e privadas já estão cientes das consequências que a circulação de notícias falsas pode acarretar na vida da população. Embora afete a todos os segmentos da sociedade, os conteúdos inverídicos podem ter efeitos ainda mais graves no âmbito da saúde pública, uma vez que estão relacionados ao bem-estar do cidadão. Por se apropriarem da espetacularização da doença, do acirramento dos temores e dos medos individuais e coletivos, esse tipo de mensagem alimenta os receios frente à eficiência e lisura da ciência, especialmente das ciências médicas.

É por isso que iniciativas como o Saúde Sem Fake News são positivas, pois oferecem subsídios para que o público possa conferir, de forma gratuita, se o conteúdo que recebeu em sua rede de amigos virtuais é verdadeiro ou não. O canal é uma saída para a checagem de informações, mas ainda precisa se firmar na vida dos usuários de redes sociais e precisa atualizar os questionamentos de forma mais incisiva - afinal a plataforma recebeu 3.860 mensagens sobre diversos temas nos três primeiros meses, mas somente 33 dúvidas foram postadas no site oficial do Saúde Sem Fake News.

O cidadão necessita, além de aprender a utilizar canais de checagem, ser capacitado para usar a internet de forma consciente com o intuito de combater às notícias falsas. É preciso ser criado outros mecanismos que proporcionem a diminuição da circulação desse tipo de conteúdo na web.

Este estudo não pretende ser conclusivo, pois a temática das fake news no âmbito da saúde pública merece maior aprofundamento e investigação, uma vez que ainda não 
existem fórmulas prontas para se lidar com o problema - o que há nos dias atuais são mecanismos e tentativas, que vão desde recursos técnicos até o investimento em educação e literacia digital. Uma possível solução para a situação seria a criação de restrições legais para combater a desinformação por parte das instituições públicas - tal como já é feito na Alemanha -, sem perder, no entanto, o respeito pela liberdade de expressão.

\section{Referências Bibliográficas}

ALLCOTT, H.; GENTZKOW, M. Social media and fake news in the 2016 election. Journal of Economic Perspectives, v. 31, n. 2, p. 211-236, 2017.

AMORIM, J. S. D. O impacto das inovações tecnológicas e das mídias digitais na concepção e na prática do jornalismo. In: MOULLIAUD, M.; PORTO, S. D. (Orgs.). O jornal: da forma ao sentido. Brasília: Editora Universidade de Brasília, 2012.

BARDIN, L. Análise de conteúdo. São Paulo: Edições 70, 2016.

BASTOS, F.; PORTO, S. D. Análise hermenêutica. In: DUARTE, J.; BARROS, A. Métodos e técnicas de pesquisa em comunicação. São Paulo: Atlas, 2017.

DELMAZO, C.; VALENTE, J. C. L. Fake news nas redes sociais online: propagação e reações à desinformação em busca de cliques. Revista Media \& Jornalismo, v. 18, n. 32, p. 155-169, 2018.

FAILLET, C. Décoder l'info - Comment Décrupter les fake news?. Paris, França: Editions Bréal, 2018.

GOMES, D. C. A. Hermenêutica e comunicação: contribuições para compreender a teoria da interpretação e sua aplicação na sociedade midiática. NAMID/UFPB, ano 9, n. ${ }^{\circ}$ 4, 2015.

HENRIQUES, C. M. P. A dupla epidemia: febre amarela e desinformação. Revista Eletrônica de Comunicação, Informação e Inovação em Saúde, v. 12, n. 1, p. 9-13, 2018.

INSTITUTO NACIONAL DO CÂNCER. Estimativa 2018: incidência de câncer no Brasil. Rio de Janeiro: Inca, 2017.

LEFÈVRE, F. Mitologia sanitária: saúde, doença, mídia e linguagem. São Paulo: Editora da Universidade de São Paulo (Edusp), 1999.

LLORENTE, J. A. A era da pós-verdade. Realidade versus percepção. Uno, n. 27, 2017. Disponível em: http://abraji.org.br/noticias/pos-verdade-e-credibilidade-no-jornalismo-estao-nocentro-do-deb ate-no-congresso-da-abraji. Acesso em: 13 mar. 2019.

ROCHA, B. A.; LAVARDA, S. L.; SILVEIRA, A. C. M. O avanço das fake news e sua retratação na mídia de referência. In: CONGRESSO DE CIÊNCIAS DA COMUNICAÇÃO DA REGIẪO SUL, 19., 2018. Cascavel (PR). Anais... Cascavel: Intercom. Disponível em: < http://portalintercom.org.br/anais/sul2018/resumos/R60-1477-1.pdf>. Acesso em: 13 mar. 2019.

RODRIGUES, A. D. Delimitação, natureza e funções do discurso midiático. In: MOULLIAUD, M.; PORTO, S. D. (Orgs.). O jornal: da forma ao sentido. Brasília: Editora Universidade de Brasília, 2012. 
SEIBT, C. L. A hermenêutica heideggeriana e a questão do conhecimento. Conjectura - Filosofia e Educação. V. 21, n 3. Caxias do Sul (RS), set./dez. 2016. P. 188-214.

SODRÉ, M. Comunicação e Voz Cidadã. In: MOUlliAUD, M.; PORTO, S. D. (Orgs.). O jornal: da forma ao sentido. Brasília: Editora Universidade de Brasília, 2012.

Antropológica do Espelho: Uma Teoria da Comunicação linear e em rede. Petrópolis (RJ): Vozes, 2002.

THOMPSON, J. Ideologia e cultura moderna: teoria social crítica na era dos meios de comunicação de massa. Petrópolis: Vozes, 2007.

VASCONCELLOS-SILVA, P. R.; CASTIEL, L. D.; GRIEP, R. H. A sociedade em risco midiatizada, o movimento antivacinação e o risco do autismo. Ciência \& Saúde Coletiva, v. 20, n. 2, p. 607-616, 2015. 